\title{
Two Types of Choice-Functional Indefinites: Evidence from Ga (Kwa)
}

\author{
Agata Renans ${ }^{1}$
}

Published online: 23 May 2017

(C) The Author(s) 2017. This article is an open access publication

\begin{abstract}
There is a longstanding discussion whether wide-scope indefinites denote choice functions that are existentially bound (Matthewson 1999; Reinhart 1997; Winter 1997) or remain free (Kratzer 1998). Data from Ga, an under-researched language spoken in Ghana, show that there are (i) wide-scope indefinites denoting existentially bound skolemized choice functions whose parameter is bound by a higher quantificational NP, (ii) free skolemized choice functions with the speaker or a higher quantificational NP as a parameter, and (iii) narrow scope quantificational indefinites. Thus the data show that both existentially bound and free skolemized choice functions are attested in natural language shedding new light on the semantics of indefinites.
\end{abstract}

Keywords Indefinites $\cdot$ Choice functions $\cdot \mathrm{Ga}$ (Kwa) language

\section{Introduction}

In the history of formal semantics, indefinites, whose small subset is exemplified in (1), have obtained many different analyses, e.g., Barwise and Cooper (1981), Heim (1982), Heim and Kratzer (1998), Kamp and Reyle (1993), Montague (1973).

\section{(1) Kofi read a/some/one book.}

Recently indefinites have been analyzed as denoting choice functions, i.e., functions from sets of individuals

Agata Renans

am.renans@ulster.ac.uk

1 Ulster University, Jordanstown, UK that pick a unique individual from any non-empty set in its domain (Kratzer 1998). ${ }^{1}$ The main controversy in a choicefunctional analysis of indefinites is whether they are existentially bound (Reinhart 1997; Winter 1997) or remain free (Kratzer 1998). ${ }^{2}$ In this paper, I argue that both free and existentially bound (skolemized) choice functions are attested in natural language, shedding new light on the semantics of indefinites in a cross-linguistic perspective.

The empirical focus of this paper is put on two indefinite determiners in $\mathrm{Ga}$, i.e., ko and kome, which show non-homogeneous scopal properties with respect to negation and quantifiers. Based on these properties, I argue that $k o$ denotes an existentially bound skolemized choice function whose parameter is bound by a higher quantificational NP, if available, and kome denotes a free skolemized choice function, whose parameter can be bound either by the speaker or a higher quantificational NP. The structure of this paper is as follows. In Sect. 2, I provide evidence that ko and kome are interpreted as indefinites and I illustrate their scopal properties. Subsequently, Sect. 3 presents the analysis of ko and kome as denoting different kinds of choice functions. Importantly, I also discuss their scopal behavior in downward entailing contexts, which were argued to be problematic for the analysis of indefinites as denoting existentially bound choice functions at the widest scope level (Chierchia 2001, Schwarz 2001, 2011). Section 4 identifies directions for future research and Sect. 5 concludes.

\footnotetext{
${ }^{1}$ For a recent non-choice-functional analysis of indefinites, see for example Brasoveanu and Farkas (2011).

${ }^{2}$ For a discussion of problems of both types of analyses, see Chierchia (2001) and Schwarz (2001, 2011).
} 


\section{Indefinites in Ga}

Ga is an under-researched Ghanaian language spoken in The Greater Accra Region by ca. 745,000 speakers. It is an SVO language with two tones: high and low. All the data stem from the author's original fieldwork in Accra in 2014 and 2016 with four Ga native speakers using the semantic field research methodologies presented in Matthewson (2004). All the language consultants grew up in a Ga speaking community and they speak Ga at home. The language consultants were students at the time of conducting the fieldwork. None of them has a background in linguistics.

\subsection{Ko, and Kome are Indefinites}

Before I discuss the scopal properties of ko, and kome, let me first provide empirical evidence that they are indeed indefinites. ${ }^{3}$ Below, I present the results of applying some diagnostics for detecting indefinites, whose design is based on the tests presented in Matthewson (1999).

The results of the diagnostic demonstrated in (2) show that NP ko and NP kome, as English indefinite NPs, can refer to two different discourse referents in a sentence. By contrast, if they were definite, they would refer to the same entities in both clauses leading to a pragmatically odd structure: ${ }^{4}$

(2) context:

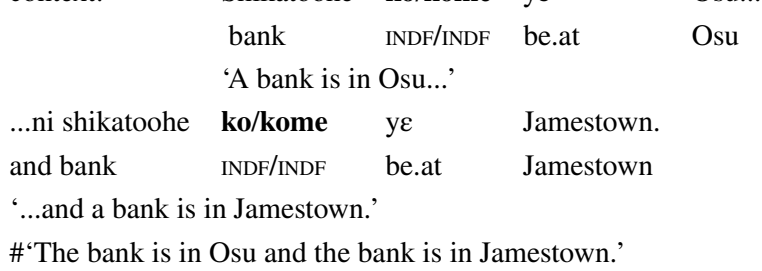

Further, it turns out that unlike definite determiners, $k o$ and kome can be used in contexts in which the discourse referent is not unique, as illustrated in (3):

(3) context: There is a tree outside the window. There are three birds on the tree.

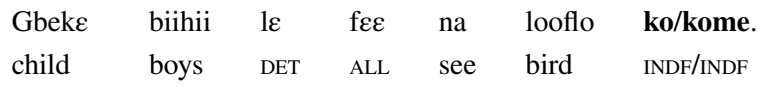

'All the boys saw a bird.'

\#'All the boys saw the bird.'

\footnotetext{
${ }^{3}$ Note that also bare NPs in Ga can obtain an indefinite interpretation. However, since a precise account of their semantics goes beyond the scope of this paper, I am leaving it for another occasion.

4 The glosses used in this paper are as follows: INDF = indefinite; DET $=$ determiner; $\mathrm{SG}=$ singular; $\mathrm{PL}=$ plural $; 3=$ Third person; $\mathrm{PRT}=$ particle; $\mathrm{NEG}=$ negation; $\mathrm{REL}=$ relativizer; $\mathrm{PFV}=$ perfective; $\mathrm{PROSP}=$ prospective. An example marked with '\#' means that the example was judged to be unacceptable in the given context and I hypothesize that it is for semantic or pragmatic reasons. Examples without any diacritics were judged as acceptable in the given context.
}

Finally, the test illustrated in (4) is based on the observation that NPs associated with the wh-remnant in sluicing constructions cannot be definite [see Matthewson (1999) and references there]. The fact that ko and kome are acceptable in sluicing constructions suggest that they are indefinites.

(4) John mii-tawo wolo ko/kome, shi mi-le tenoniji. John PROG-look.for book INDF/INDF but 1sG-not. which know

'John is looking for a book but I do not know which.'

\#'John is looking for the book but I do not know which.'

\subsection{Ko, Kome are Singular Indefinites}

Both ko and kome are singular indefinites. Kome derives from ekome 'one' and the cardinality one forms part of its meaning. This claim is based on the data presented in (5)-(7), which show that kome can only combine with singular count nouns:

(5) Singular COUNT NOUN:

Q: What did Kofi buy yesterday?

A: Kofi he adafitswawolo kome nye. Kofi buy newspaper INDF yesterday 'Kofi bought (one) newspaper yesterday.'

(6) Plural count noun:

Q: What did Kofi buy yesterday?

A: \#Kofi he adafitswawo-ji kome nye. Kofi buy newspaper-PL INDF yesterday 'Kofi bought one newspapers yesterday.'

(7) Mass noun:

Q: What did Lisa buy yesterday?

\begin{tabular}{|c|c|c|c|}
\hline 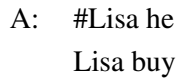 & $\begin{array}{l}\text { fo } \\
\text { oil }\end{array}$ & $\begin{array}{l}\text { kome } \\
\text { INDF }\end{array}$ & $\begin{array}{l}\text { nye. } \\
\text { yesterday }\end{array}$ \\
\hline
\end{tabular}

Also ko combines with singular count nouns but not with plural count nouns, as shown below:

(8) Singular COUNT NOUN:

Q: What did Kofi buy yesterday?

A: Kofi he adafitswawolo ko nye. Kofi buy newspaper INDF yesterday 'Kofi bought (one) newspaper yesterday.'

(9) Plural Count noun:

Q: What did Kofi buy yesterday?

B: \#Kofi he adafitswawo-ji kome nye. Kofi buy newspaper-PL INDF yesterday 'Kofi bought one newspapers yesterday.' 
However, the data with mass nouns are more complicated. It seems that in general $k o$ cannot combine with mass nouns. However, if one has in mind a particular type or brand of the given NP, $k o$ becomes acceptable. By way of illustration consider (10):

(10) Mass nouns:

Q: What did Lisa buy yesterday?

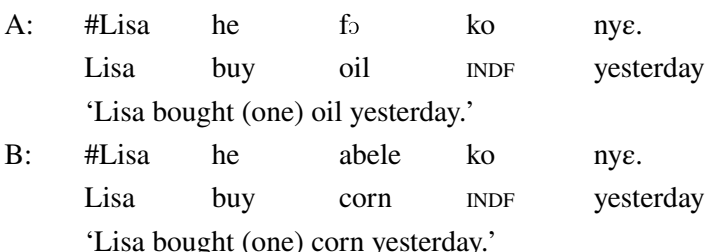

In the case of (10-A) the language consultants gave a comment that it is acceptable if one refers to the particular type of oil. The same holds for (10-B). It is fine if one talks about the particular type of corn but not if one talks about corn in general. This issue should be further examined empirically in order to determine whether it is or it is not another dimension, in addition to the differences in the scopal properties of ko and kome discussed in the next subsection, in which the semantics of both indefinites differ. ${ }^{5}$

\subsection{Scopal Properties of Ko and Kome}

Interestingly, ko, and kome exhibit non-homogeneous scopal properties with respect to various operators, e.g., negation and quantifiers. ${ }^{6}$ First, it turns out that whereas ko can take both wide and narrow scope with respect to negation, kome can only take a wide scope. Consider (11). Since the context specifies that Kofi bought a lot of fish, it clashes

\footnotetext{
5 Another question is whether ko and kome also differ along other dimensions, such as existence, indifference, ignorance implications, epistemic specificity, etc. To check it, one should examine whether the minimal pairs with ko and kome which exhibit the same scopal properties have the same semantics and pragmatics. In this paper however I am concentrating on the scopal properties of ko and kome; their other properties have to await future research. Thank you to the anonymous reviewers for asking about it.

6 The scopal properties of kome are similar to the scopal properties of a certain and singular some in English (Farkas 2002). However, the more precise comparison between some, certain and ko, kome is not possible at this stage of research due to the lack of the conclusive data regarding their scopal interaction with intensional predicates as well as their additional connotations, like a free choice component or an ignorance implication. Importantly, if these additional connotations are indeed attested in $\mathrm{Ga}$, it would be important to examine whether it is possible to derive the scopal properties of ko and kome from the basic constraints which are responsible for their epistemic connotations, e.g., in line with Farkas (2002). I postpone this issue for future research, concentrating in this paper on scopal properties of $k o$ and kome with respect to negation and quantifiers. Thank you to the anonymous reviewer who asked about it.
}

with the narrow-scope interpretation which would lead to the meaning that Kofi didn't buy any fish.

(11) WIDE-SCOPE INTERPRETATION context: Kofi bought a lot of fish, but

$\begin{array}{ll}\text { E-he-ko } & \text { loo } \\ \text { 3sG-buy-PFV.NEG } & \text { fish } \\ \text { 'He didn't buy a certain fish.' } & \end{array}$

ko/kome

'He didn't buy a certain fish.'

INDF/INDF

The context in (12), on the other hand, requires a narrowscope interpretation. Since the context directly specifies that Kofi didn't buy any fish, a wide scope interpretation which says that Kofi didn't buy a certain fish is ruled-out.

(12) NARROW-SCOPE INTERPRETATION

context: Kofi went to the market yesterday. He bought vegetables, shoes, and toys but he didn't buy any fish.

$\begin{array}{lll}\text { Kofi he-ko } & \text { loo } & \text { ko/\#kome } \\ \text { Kofi buy-PFV.NEG } & \text { fish } & \text { INDF/INDF } \\ \text { 'Kofi didn't buy any fish.' } & & \end{array}$

Second, whereas kome can obtain both a constant and a covarying interpretation with respect to quantifiers, as suggested by its acceptability in the context of (13) and (14), ko can only get a covarying interpretation, as suggested by their acceptability in the context of (14) and its unacceptability in the context of (13). The context in (13) specifies that all women were reading the same book and thus only a constant interpretation of the indefinite NP 'a book' is felicitous in this context. By contrast, the context in (14) states that every woman read a different book and therefore only a covarying interpretation of the indefinite is felicitous in this context. ${ }^{7}$

\section{(13) CONSTANT INTERPRETATION}

context: There were four women in the library. It looked really funny because all of them were reading one book.

$\begin{array}{llllll}\text { Yei } \quad l \varepsilon & \text { fec } & \text { kane } & \text { wolo } & \text { \#ko/kome. } \\ \text { women } & \text { DET } & \text { every } & \text { read } & \text { book } & \text { INDF/INDF } \\ \text { 'Every woman read some book.' } & & \end{array}$

(14) COVARYING INTERPRETATION

context: When I came to the library yesterday, four women were reading a book. Each of them was reading a different book.

$\begin{array}{llllll}\text { Yei } & l \varepsilon & \text { fec } & \text { kane } & \text { wolo } & \text { ko/kome. } \\ \text { women } & \text { DET } & \text { every } & \text { read } & \text { book } & \text { INDF/INDF }\end{array}$

'Every woman read some book.'

\footnotetext{
7 An anonymous reviewer asked whether $k o$ is acceptable in the cases, in which a co-varying interpretation is pragmatically odd, as in (i)

(i) Every participant at the ceremony walked up to a big table in the middle of the room an placed an offering on it.

I plan to check it empirically during my next field trip. Thank you for pointing my attention to this example.
} 
In addition, both ko and kome can obtain an intermediate scope interpretation. By way of illustration the intermediate scope interpretation, consider (15), taken from Reinhart (1997):

(15) Most linguists have looked at every analysis that solves some problem.

Crucially, (15) can obtain three interpretations, i.e., a narrow, wide, and intermediate scope interpretation, depending on the scope of the indefinite NP some problem. All three interpretations are listed below:

(16) a. There is some problem,

WIDE SCOPE INTERPRETATION

such that most linguists

have looked at every analysis that solves that problem.

b. Most linguists have looked NARROW SCOPE INTERPRETATION at every analysis that solves a problem.

c. For most linguists, there is some problem, such that they have looked at every analysis that solves that problem.

INTERMEDIATE SCOPE INTERPRETATION

The intermediate scope interpretation of (15), explicated in (16-c), is the one in which most linguists chose one problem to work on but the choice of the problem varies with the linguist. This interpretation is presented in the context of (17). Crucially, the acceptability of ko and kome in this context suggests that both of them can obtain the intermediate scope interpretation.

(17) context: Four linguists chose one linguistic problem to work on. Linguist 1 chose the syntax of Ga, linguist 2 chose the syntax of Akan, linguist 3 chose the phonology of Ewe, linguist 4 chose the morphology of Avatime. Linguists 1, 2, and 3 , but not 4 , read all the analyses solving the respective problem.

\begin{tabular}{|c|c|c|c|c|}
\hline Otsiamii & pii & ekw & susumi & saji \\
\hline linguist & most & have.looked & analysis & analysis \\
\hline 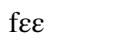 & ni & yes & boa & sane \\
\hline every & that & help & solve & problem \\
\hline kome/ko & naaboam. & & & \\
\hline INDF/INDF & solve & & & \\
\hline
\end{tabular}

A summary of the discussed scopal properties of $k o$, and kome is presented in Table 1. A formal semantic account of their properties, in turn, is discussed in the next section.
Table 1 Scopal properties of ko and kome

\begin{tabular}{llll}
\hline & $\begin{array}{l}\text { Intermediate } \\
\text { scope }\end{array}$ & Negation & Quantifiers \\
\hline Ko & $\checkmark$ & Wide, narrow & Covarying \\
Kome & $\checkmark$ & Wide & Constant, covarying \\
\hline
\end{tabular}

\section{Analysis}

Based on the data presented in Sect. 2, I argue that both $k o$ and kome denote skolemized choice functions. The strongest evidence for the analysis of the indefinites as denoting choice functions (Chierchia 2001, Kratzer 1998, Matthewson 1999, Reinhart 1997, Winter 1997) is the availability of intermediate scope readings. ${ }^{8}$ The intermediate scope interpretation with ko and kome indefinites in (17) shows that they can be neither quantificational nor referential. They cannot be quantificational, because quantifiers cannot move out of syntactic islands and therefore the quantificational analysis predicts the unacceptability of ko and kome in the context of (17), contrary to fact. Moreover, they cannot be referential in (17), because the linguists didn't choose one and the same problem for all of them but they chose different problems to solve. In the next subsection, I will explicate the semantics of ko and kome as denoting (skolemized) choice functions and I will demonstrate how this analysis accounts for the data presented in Sect. 2.3.

\subsection{Ko, Kome and Skolemized Choice Functions}

A choice function (CF) is a function of type $\langle\langle e, t\rangle, e\rangle$ which takes a set as its argument and returns one element from that set:

\section{(18) A choice function is a function from sets of individuals that picks a unique individual from any non-empty set in its domain (Kratzer 1998).}

There are two competing approaches to choice functions: Whereas Reinhart (1997), Winter (1997) and Matthewson (1999) argue that choice functions are existentially bound, Kratzer (1998) and Matthewson (2001) argue that they remain free. For example, under the analysis of the indefinite determiner $a$ as denoting an existentially bound CF, the sentence in (19) obtains the interpretation in (19-a) and under the analysis of $a$ as denoting a free CF, it recieves the interpretation in (19-b), where $f$ is a variable ranging over choice functions. In the latter, the value of the CF is provided by the context, which usually is the one intended by the speaker:

\footnotetext{
${ }_{8}$ For the opposite view, see for example Guerts $(2000,2002)$.
} 
(19) Kofi read a book.

a. $\exists f$ (Kofi read $f$ (book))

$\approx$ There is a way of choosing a book such that Kofi read this book.

b. Kofi read $f$ (book)

$\approx$ Kofi read a book chosen in a way known to the speaker.

Choice functions can also be skolemized, i.e., they can take an additional covert pronominal index (also called the parameter or the skolem index). The index, as overt pronouns, can be either interpreted with respect to the assignment function, usually relativized to the speaker, or can be bound by a higher quantificational NP. The former leads to the constant interpretation in (20-a) and the latter triggers the covarying scope interpretation in (20-b):

(20) Every student read a book.

a. every student read $f_{1}$ (book)

$\approx$ I know a way of choosing a book such that every student read the book chosen that way.

b. every student ${ }_{z}$ read $f_{z}$ (book)

$\approx$ Every student read a book chosen in a way relative to every student.

Analyzing indefinites as denoting skolemized choice functions can account for the intermediate scope interpretation. For example, the intermediate reading of (17) in Kratzer's (1998) approach to CF is as in (21):

(21) for most $x[$ linguist $(x) \rightarrow \forall z[$ analysis $(z) \wedge z$ solves $f_{x}($ problem $) \rightarrow x$ looked at $\left.\left.z\right]\right]$

$\approx$ For most linguists, there is a way of choosing a problem such that they have looked at every analysis that solves that problem.

As it has already been mentioned, I propose that both ko and kome denote skolemized choice functions. The question is whether they are bound or free, and what the possible binders of their parameters are. I argue that the answers for these questions are provided by different scopal properties of ko and kome presented in Sect. 2.3.

\subsubsection{Interaction with Negation}

I propose that in a semantic fieldwork situation, interaction with negation is a good test method for determining whether a CF denoted by an indefinite is existentially bound or not. Crucially, a narrow scope interpretation with respect to negation is only possible if a CF denoted by an indefinite is existentially bound. Otherwise, only a wide scope interpretation is available. Consider (22):
(22) Kofi didn’t buy any fish.

With an existentially bound CF both a wide scope interpretation, as in (23-a), and a narrow scope interpretation, as in (23-b), is possible, because negation can scope above or below existential closure: ${ }^{9}$

(23) a. $\exists f\left[\neg\right.$ buy [ Kofi, $f_{1}$ ( fish ) $\left.]\right] \approx$ As for the speaker, there is a way of choosing a fish such that Kofi didn't buy it (there is a fish that Kofi didn't buy.)

b. $\neg \exists f\left[\right.$ buy [ Kofi, $f_{1}($ fish $\left.\left.)\right]\right] \approx$ As for the speaker, there is no way of choosing a fish such that Kofi bought it

(Kofi didn’t buy any fish.)

With a free $\mathrm{CF}$, on the other hand, only a wide scope interpretation is possible, because there is no other operator that negation could scope over: ${ }^{10}$

(24) $\neg$ buy [ Kofi, $f_{1}($ fish ) $] \approx$ The speaker knows a way of choosing a fish such that Kofi didn't buy it (there is a fish that Kofi didn't buy.)

Since ko can get both a wide and a narrow scope interpretation with respect to negation, I argue that it denotes an existentially bound skolemized CF. By contrast, since kome can only get a wide scope interpretation with respect to negation, it denotes a free skolemized choice function.

\subsubsection{Interaction with Quantifiers}

The interaction with quantifiers, on the other hand, can detect possible parameter (skolem index) binders. If an indefinite has the speaker as its parameter, it gets a constant interpretation. Conversely, if the parameter is bound by a higher quantificational NP, an indefinite gets a covarying interpretation. Consider (25):

(25) Every woman read some book.
${ }_{9}$ I propose that both ko and kome denote skolemized CFs. Since there is no binder that could bind the index in (23), its value is provided by the context, i.e., by the assignment function. Even though in the case of (b) the CF is bound by the context, due to the presence of existential closure it does not obtain a wide scope interpretation.

10 Note that the paraphrases for contextually bound wide scope indefinites are intended to suggest that the speaker knows the way of choosing a relevant NP rather than that the speaker knows the relevant NP. Therefore, they should not be understood as epistemically specific, see Kratzer (2003). Thank you to the anonymous reviewer who asked for clarification. 
The representations of (25) given in (26) illustrate what happens when the parameter is bound by the speaker. In both cases, i.e., when the CF is existentially closed or remains free, the indefinite obtains a constant interpretation:

(26) a. $\exists f \forall z\left[\operatorname{woman}(z) \rightarrow \operatorname{read}\left(z, f_{1}(\right.\right.$ book $\left.\left.)\right)\right]$

$\approx$ As for the speaker, there is a way of choosing a book such that every woman read a book chosen that way.

b. $\forall z\left[\operatorname{woman}(z) \rightarrow \operatorname{read}\left(z, f_{1}(\right.\right.$ book $\left.\left.)\right)\right]$

$\approx$ The speaker knows a way of choosing a book such that every woman read a book chosen that way

By contrast, if the parameter is bound by a higher quantificational NP, then the indefinite invariably obtains a covarying interpretation. ${ }^{11}$

(27) a. $\exists f \forall z\left[\operatorname{woman}(z) \rightarrow \operatorname{read}\left(z, f_{z}(\right.\right.$ book $\left.\left.)\right)\right]$

$\approx$ There is a way of choosing a book relative to every woman such that she read a book chosen that way.

b. $\forall z\left[\operatorname{woman}(z) \rightarrow \operatorname{read}\left(z, f_{z}(\right.\right.$ book $\left.\left.)\right)\right]$

$\approx$ For every woman there is a way of choosing a book such that she read a book chosen that way.

In Sect. 2.3, it was shown that whereas kome can get both a constant and a covarying interpretation, $k o$ can only get a covarying interpretation. Building on these data and the observations presented in (26) and (27), I argue that while the parameter of kome can be bound either by the speaker or a higher quantificational NP, the parameter of $k o$ can only be bound by a higher quantificational NP (if available).

Putting all the elements together, I propose that kome denotes a free skolemized CF whose pronominal parameter can be bound either by the context or by a wider scope quantificational NP. Ko, on the other hand, denotes an existentially bound skolemized CF, whose parameter is bound by a higher quantificational NP (if available). ${ }^{12}$

\footnotetext{
11 Note that in the case of indefinites denoting an existentially bound $\mathrm{CF}$, it does not matter whether $\exists$ scopes over $\forall$ or vice versa: since in both cases the parameter is bound by the speaker in (25) and by the higher quantificational NP in (26), both give rise to the same truth conditions.

12 The fact that one needs two types of choice functions, one contextually bound and one existentially bound, together with two different binding mechanisms to account for the data from one language complicates significantly the choice-functional analysis of indefinites. Especially, if one takes into consideration that Kratzer (1998) proposed the analysis of indefinites in terms of contextually bound choice functions in order to simplify the special binding mechanisms which were needed in order to account for the scopal behavior of indefinites under their analysis as existentially bound choice functions. I leave for future research the question how to simplify the analysis I put forward. Thank you to the reviewer for pointing this out to me.
}

In the next subsection, I will discuss the main arguments against the choice functional analysis of indefinites (Chierchia 2001, Schwarz 2001, 2011). In particular, I will discuss the empirical predictions of this analysis in downward entailing contexts and show that the indefinites in Ga give rise to the predicted readings.

\subsection{Ko and Kome in Downward Entailing Contexts}

Chierchia (2001) and Schwarz (2001, 2011) claim that existentially bound CFs (with the existential closure taking the widest scope, as it is argued for ko) over-generates. In particular, Schwarz (2001) showed that whereas the LF in (28) interprets an indefinite as a narrow scope existential quantifier when $\alpha$ is upward entailing, it interprets an indefinite as a narrow scope universal quantifier when $\alpha$ is downward entailing. Importantly, the latter reading turns out to be unattested in English.

(28) $\exists f\left[\alpha \lambda_{1}\left[t_{1}\right.\right.$ submitted $f\left[\right.$ paper he $\mathrm{e}_{1}$ had written $\left.\left.]\right]\right]$

a. UPWARD ENTAILING $\alpha$

Every candidate submitted a paper he had written.

$\Rightarrow$ a paper is interpreted as a narrow scope existential quantifier

b. Downward EnTAILING $\alpha$

No student submitted a paper he had written.

$\Rightarrow$ a paper is interpreted as a narrow scope universal quantifier

For illustration, consider (29), taken from Schwarz (2011):

(29) Every candidate submitted a paper he had written.

(30) a. every candidate $\lambda_{1}\left[\exists f\left[\mathrm{t}_{1}\right.\right.$ submitted $f$ [paper he ${ }_{1}$ had written]]]

b. $\quad \exists f$ [every candidate $\lambda_{1}\left[\mathrm{t}_{1}\right.$ submitted $f$ [paper he ${ }_{1}$ had written]]]

Schwarz (2011, p. 887)

(30-a) conveys the interpretation that for every candidate there is a way of choosing a paper he had written such that he submitted that paper. Importantly, (30-b) can express the same truth conditions. Namely, it conveys the meaning that there is a CF such that every candidate submitted a paper he had written chosen by that CF. This reading is illustrated in the scenario below, taken from Schwarz (2011), in which the capital letters and numbers in the curly brackets represent the papers a candidate wrote. The submitted papers are underlined:

$\begin{array}{lll}\text { (31) Alan: } & & \{\underline{A 1}, A 2, A 3\} \\ \text { Bob: } & & \{\underline{B 1}, B 2\} \\ \text { Carl: } & & \{\underline{C 1}, C 2, \underline{C 3}\}\end{array}$

Schwarz (2011, p. 887) 
Crucially, the existence of the CF as in (32) ensures that (30-b) comes out true:

$$
\begin{array}{lll}
\text { (32) Alan: } & \{\underline{A 1}, A 2, A 3\} \rightarrow \mathrm{A} 1 \\
\text { Bob: } & \{\underline{B 1}, B 2\} \rightarrow \mathrm{B} 1 \\
\text { Carl: } & \{\underline{C 1}, C 2, \underline{C 3}\} \rightarrow \mathrm{C} 1
\end{array}
$$

Schwarz (2011, p. 887)

It follows that (30-b) is true just in case every candidate submitted at least one paper he had written.

The situation is dramatically different in downward entailing contexts. Consider (33) and the two LFs in (34):

(33) No candidate submitted a paper he had written.

(34) a. no candidate $\lambda_{1}\left[\exists f\left[\mathrm{t}_{1}\right.\right.$ submitted $f$ [paper he ${ }_{1}$ had written]]]

b. $\exists f$ [no candidate $\lambda_{1}\left[\mathrm{t}_{1}\right.$ submitted

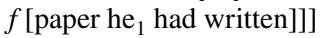

Schwarz (2011, p. 887)

In that case (34-a) conveys the interpretation that for no candidate there is a way of choosing a paper he had written such that he submitted that paper, i.e., for no candidate there is a paper he wrote that he submitted. By contrast, (34-b) expresses the much weaker interpretation that there is a way of choosing a paper the candidate had written such that no candidate submitted that paper, i.e., (34-b) is true just in case no candidate submitted every paper he wrote. It follows that whereas (34-a) is false in the scenario discussed above, (34-b) turns out to be true in that scenario, for example due to the existence of the CF presented below:

$$
\begin{array}{ll}
\text { (35) Alan: } & \{\underline{A 1}, A 2, A 3\} \rightarrow \mathrm{A} 2 \\
\text { Bob: } & \{\underline{B 1}, B 2\} \rightarrow \mathrm{B} 2 \\
\text { Carl: } & \{\underline{C 1}, C 2, \underline{C 3}\} \rightarrow \mathrm{C} 2
\end{array}
$$

Schwarz (2011, p. 887)

Now, Schwarz $(2001,2011)$ argues that (33) cannot obtain the interpretation in (34-b), i.e., (33) is not true in the scenario of (35), contrary to what is predicted under the analysis of (33) given in (34-b). Therefore, the analysis of English indefinites as denoting CFs which are existentially bound at the widest scope level gives rise to unattested readings. For that reasons, Schwarz (2001, 2011) building on Chierchia (2001) proposed restrictions on the distribution of the existential closure that bound a CF:
(36) a. Condition A: a choice function variable and its existential closure cannot be seperated by an operator binding a variable in the indefinite.

b. Condition B: existential closure with non-widest scope is limited to the immediate scope of a quantifier binding a variable in the indefinite (whose function variable existential closure binds).

Schwarz (2011, pp. 888-889)

Crucially, data from Ga suggest that sentences with $k o$, which I argue denote an existentially bound CF at the widest scope level, give rise to the predicted readings which are unattested in English. Thus one does not have to impose any additional restrictions on the distribution of the existential closure in Ga. ${ }^{13}$ Consider the context in (37) and a sentence with the indefinites in downward entailing context:

(37) context: There were three students: Mary, Sue, and Joe. All of them wrote letters, but none of them sent all of them.

$\begin{array}{lllll}\text { Nikaselo } & \text { ko } & \text { k } \varepsilon & \text { e-wolo } & \text { ko/kome } \\ \text { student } & \text { INDF } & \text { and } & \text { 3sG-letter } & \text { INDF/INDF } \\ \text { ni } & \text { e-Ima } & \text { le } & \text { e-ya-aa. } & \\ \text { REL } & \text { 3sG-write } & \text { DET } & \text { 3sG-send-NEG } & \\ \text { 'No student send a letter (s)he wrote.' } & \end{array}$

The scenario can be illustrated schematically as below, where the capital letters with numbers are the letters written by students and the underlined ones are the letters that the students sent: ${ }^{14}$
(38) Mary: $\{\underline{M 1}, M 2, M 3\}$
Sue: $\quad\{\underline{S 1}, \underline{S 2}, S 3\}$
Joe: $\quad\{\underline{J 1}, J 2, \underline{J 3}\}$

A semi formal representation of (37) with $k o$ is given in (39-a) and with kome in (39-b):

(39) a. $\exists f\left[\right.$ no student $\lambda_{1}\left[\mathrm{t}_{1}\right.$ sent $f\left[\right.$ letter he $\mathrm{e}_{1}$ wrote $\left.\left.]\right]\right] \quad$ ко

b. no student $\lambda_{1}\left[\mathrm{t}_{1}\right.$ sent $f_{1}$ [letter he wrote $\left._{1}\right] \quad$ KOME

In that case, as predicted, both (39-a) and (39-b) turn out to be true. (39-a) conveys the meaning that there is a way of choosing a letter written by the student in such a way that

\footnotetext{
13 Note that this pose a serious challenge for an analysis of indefinites in a cross-linguistic perspective. Namely, there are distributional restrictions in the analysis of indefinites in English which then have to be suspended in order to account for Ga data. A development of the unified analysis of indefinites is left for future research. Thank you to the anonymous reviewer for pointing my attention to this issue.

14 The language consultants were presented with the scenario in (38), i.e., they judged the acceptability of (37) precisely in the context of (38).
} 
no student sent a letter chosen that way. It comes out true for example due to the CF presented in (40):

$$
\begin{array}{lll}
\text { (40) } & \text { Mary: } & \{\underline{M 1}, M 2, M 3\} \rightarrow \mathrm{M} 2 \\
\text { Sue: } & \{\underline{S 1}, \underline{S 2}, S 3\} \rightarrow \mathrm{S} 3 \\
\text { Joe: } & \{\underline{J 1}, J 2, \underline{J 3}\} \rightarrow \mathrm{J} 2
\end{array}
$$

The LF demonstrated in (39-b) also conveys a proper interpretation of the target sentence in (37). It can be paraphrased as: the speaker knows a way of choosing a letter a student wrote in such a way that no candidate sent the letter chosen that way. Since the context provides such a letter, e.g., letter M2 was sent by no candidate, the target sentence in (37) with kome was judged as acceptable in the given scenario. ${ }^{15}$

Coming back to Schwarz's $(2001,2011)$ examples, all of them are such that there is no overlap in the papers written by different candidates, i.e., 'for no two candidates $\mathrm{x}$ and $\mathrm{y}$, the set of papers $\mathrm{x}$ wrote is also the set of papers $\mathrm{y}$ wrote.' Schwarz (2011, p. 895). By contrast, in what follows, I will show that the analysis of ko and kome can also account for the different scopal behavior of ko and kome in downward entailing contexts of (41) and (46), in which there is an overlap in the set of books chosen by the students to read. Consider (41):

$$
\begin{aligned}
& \text { context: There were three women in the literature course: } \\
& \text { Mrs Smith, Mrs Müller, and Mrs Laryea. They were } \\
& \text { supposed to read three books of their choice. Mrs Smith } \\
& \text { chose 'Anna Karenina,' 'Gone with the wind,' and } \\
& \text { 'Madame Bovary.' She read 'Anna Karenina' and 'Gone } \\
& \text { with the Wind' but she didn't read 'Madame Bovary.' Mrs } \\
& \text { Müller chose 'The Hobbit,' 'Pride and Prejudice,' and } \\
& \text { 'Madame Bovary.' She read 'The Hobbit' and 'Pride and } \\
& \text { Prejudice' but she didn't read 'Madame Bovary.' Mrs Lar- } \\
& \text { yea chose 'The Lord of the Rings,' 'Anna Karenina,' and } \\
& \text { 'Madame Bovary.' She read 'The Lord of the Rings' and } \\
& \text { 'Anna Karenina' but she didn't read 'Madame Bovary.' }
\end{aligned}
$$

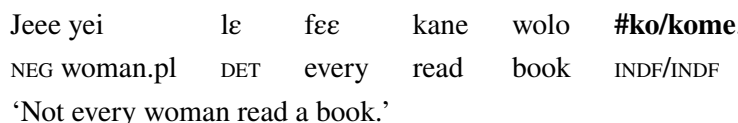

\footnotetext{
15 Note, however, that in order to draw definite conclusions regarding the semantics of indefinites in sentences such as (37) more work should be done on the semantics of negative quantifiers. Even though the data I gathered thus far show that the quantifier 'no' comes out as the result of the interaction between the indefinite $k o$ and negation attached to a verb, as demonstrated in (i), one cannot entirely exclude the possibility that the sentence in (37) was understood by the language consultants as 'A certain student didn't send a letter (s)he wrote.' The question whether it is really the case should be further investigated.
}

(i) context: There were three students: Mary, Sue, and Joe. I have recommended to read 'Anna

Karenina' but none of them read it.

Nikaselo ko kane-ee wolo le ni mi fa $l \varepsilon$. student INDF read-NEG book DET REL 1SG recommend DET 'No student read a book I have recommended.'
The context of (41) is presented schematically in (42), where the capital letters stand for books' titles and the underlined capital letters for the books read by the respective woman:

$$
\begin{array}{lll}
\text { (42) } & \text { Mrs Smith: } & \{\underline{\mathrm{AK}}, \underline{\mathrm{GW}}, \mathrm{MB}\} \\
\text { Mrs Müller: } & \{\underline{\mathrm{TH}}, \underline{\mathrm{PP}}, \mathrm{MB}\} \\
\text { Mrs Laryea: } & \{\underline{\mathrm{LR}}, \underline{\mathrm{AK}}, \mathrm{MB}\}
\end{array}
$$

The analysis of $k o$ as an existentially bound CF with a higher quantificational NP as the parameter can account for the unacceptability of $k o$ in the context of (42). The semiformal representation of the target sentence with $k o$ is given in (43).

\section{(43) $\neg \exists f\left[\right.$ every woman $z$ read $f_{z}$ (book)]}

It says that there is no way of choosing a book such that every woman read a book chosen by 'her CF.' Crucially, it is false in the context of (41), because there is a way of choosing a book such that every woman read a book chosen that way, as illustrated in (44).

\section{(44) Mrs Smith: $\{\underline{\mathrm{AK}}, \underline{\mathrm{GW}}, \mathrm{MB}\} \rightarrow \mathrm{AK}$ \\ Mrs Müller: $\{\underline{\mathrm{TH}}, \underline{\mathrm{PP}}, \mathrm{MB}\} \rightarrow \mathrm{PP}$ \\ Mrs Laryea: $\{\underline{\underline{\mathrm{LR}}}, \underline{\mathrm{AK}}, \mathrm{MB}\} \rightarrow \mathrm{LR}$}

Conversely, the target sentence with kome is judged to be acceptable in the context of (41). Kome denotes a free skolemized CF. When the value of the skolem index of kome is relativized to the speaker, it obtains the following representation:

(45) $\neg\left[\right.$ every woman read $f_{1}$ (book)]

(45) says that the speaker knows a way of choosing a book such that it is not the case that every woman read this book. This is true in the context of (41), because it is possible to choose a book in the relevant way. For example, 'Madame Bovary' is the book that was not read by every woman (in fact nobody read it). Now, consider (46):

(46) context: The same as before, but this time Mrs Smith didn't read 'Madame Bovary', Mrs Müller didn't read 'Pride and Prejudice', and Mrs Smith didn't read 'Anna Karenina.' They read all other books they chose.

$\begin{array}{lllllll}\text { Jeee } & \text { yei } & \text { le } & \text { fec } & \text { kane } & \text { wolo } & \text { \#ko/kome. } \\ \text { NEG } & \text { woman.PL } & \text { DET } & \text { every } & \text { read } & \text { book } & \text { INDF/INDF } \\ \text { 'Not every woman read a book. } & & & & \end{array}$

'Not every woman read a book.'

Again, the context is presented schematically in (47), where the capital letters stand for books' titles and the underlined capital letters for the books read by the respective woman: 


\section{(47) Mrs Smith: $\quad\{\underline{\mathrm{AK}}, \underline{\mathrm{GW}}, \mathrm{MB}\}$ \\ Mrs Müller: $\{\underline{\mathrm{TH}}, \mathrm{PP}, \underline{\mathrm{MB}}\}$ \\ Mrs Laryea: $\{\underline{\mathrm{LR}}, \mathrm{AK}, \underline{\mathrm{MB}}\}$}

The same as in the example discussed before, the target sentence with $k o$ is unacceptable in the context of (47). Again, it is judged to be wrong because there is a way of choosing a book, relativized to every woman, such that the respective woman read a book chosen by 'her CF', contrary to what is suggested by the formal representation of the target sentence with $\mathrm{ko}$ :

\section{(48) $\neg \exists f\left[\right.$ every woman ${ }_{z}$ read $f_{z}$ (book)]}

Conversely, the target sentence with kome is judged to be acceptable, because kome invariably takes a wide scope with respect to negation. Consider (49) with the speaker as the parameter:

(49) $\neg\left[\right.$ every woman read $f_{1}$ (book)]

It can be paraphrased as: the speaker knows a way of choosing a book such that it is not the case that every woman read this book. This is true in the context of (46), because for example 'Anna Karenina' was not read by every woman. Finally, consider the context in (50) and its schematic representation in (51):

(50) context: There were four women in the library. Three of them were reading a book, i.e., the first one was reading 'Pride and Prejudice,' the second 'Gone with the Wind,' and the third 'Anna Karenina.' The fourth woman was writing an article, she was not reading any book.

Jee yei le fec kane wolo ko/kome.

NEG woman.PL DET every read book INDF/INDF

'Not every woman read a book.'

(51) woman $1:\{\underline{P P}\}$

woman 2: $\{\underline{\mathrm{GW}}\}$

woman $3:\{\underline{\mathrm{AK}}\}$

woman $4:\{\emptyset\}$

Now, the target sentences with both ko and kome are judged to be acceptable by the Ga native speakers. Consider (52). The interpretation conveyed by the LF in (52), namely that there is no way of choosing a book relative to every woman such that she read a book chosen by 'her CF,' turns out to be true in the context of (51). It is the case because there is no way of choosing a book for woman 4 . Therefore the target sentence with ko was judged to be acceptable by the language consultants.

(52) $\neg \exists f\left[\right.$ every woman $z$ read $f_{z}$ (book) $]$
Also the interpretation conveyed by (53) is true in the context of (51). (53) expresses the meaning that the speaker knows the way of choosing a book in such a way that not every woman read a book chosen that way. 'Pride and Prejudice' is for example such a book in the context of (51) and therefore the target sentence with kome was judged to be acceptable in the context of (51).

\section{(53) $\neg$ [every woman read $f_{1}$ (book)]}

The remaining open issue is the question why in downward entailing contexts the language consultants prefer the interpretation of $k o$ in which the negation scopes over the existential closure, i.e., they prefer (54-a) over (54-b):

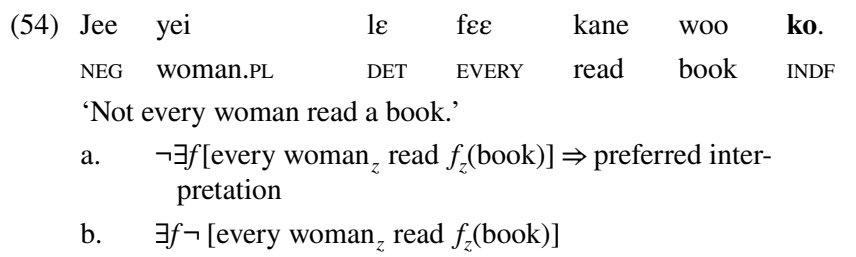

Crucially, (54-b) predicts (54) to be acceptable in the context of (41) and (46) and to be unacceptable in the context of (50). The contexts are repeated in a schematic way below in (55), (56) and (57). Again, the capital letters are the book titles chosen by the women and the underlined ones are those that the women actually read. Crucially, (54b) conveys the interpretation that there is a way of choosing a book in such a way that it is not the case that every woman read a book chosen by 'her CF.' Importantly, it is true in the scenario of (55) and (56), because in both scenarios for every woman there is a book such that she did not read it. However, in both cases the target sentence with $k o$ (54) was judged to be unacceptable, suggesting that ko was interpreted as in (54-a), which properly models the discussed data, as it was demonstrated above.

$\begin{array}{lll}\text { (55) Mrs Smith: } & \{\underline{\mathrm{AK}}, \underline{\mathrm{GW}}, \mathrm{MB}\} \rightarrow \mathrm{MB} \\ & \text { Mrs Müller: } & \{\underline{\mathrm{TH}}, \underline{\mathrm{PP}}, \mathrm{MB}\} \rightarrow \mathrm{MB} \\ \text { Mrs Laryea: } & \{\underline{\mathrm{LR}}, \underline{\mathrm{AK}}, \mathrm{MB}\} \rightarrow \mathrm{MB} \\ \text { (56) } & \text { Mrs Smith: } & \{\underline{\mathrm{AK}}, \underline{\mathrm{GW}}, \mathrm{MB}\} \rightarrow \mathrm{MB} \\ & \text { Mrs Müller: } & \{\underline{\mathrm{TH}}, \underline{\mathrm{PP}}, \underline{\mathrm{MB}}\} \rightarrow \mathrm{PP} \\ & \text { Mrs Laryea: } & \{\underline{\mathrm{LR}}, \mathrm{AK}, \underline{\mathrm{MB}}\} \rightarrow \mathrm{AK}\end{array}$

In addition, (54-b) predicts (54) to be unacceptable in the scenario of (57). Again, (54-b) can be paraphrased as: there is a way of choosing a book relative to every woman in such a way that it is not the case that every woman read the book chosen by 'her CF.' However, in (57) there is no way of choosing a book for every woman, because the forth woman did not read a book at all. 


\section{(57) woman 1: $\quad\{\underline{P P}\}$ \\ woman 2: $\quad\{\underline{\mathrm{GW}}\}$ \\ woman 3: $\quad\{\underline{\mathrm{AK}}\}$ \\ woman 4: $\{\emptyset\}$}

It seems that the interpretation of $k o$ as denoting a $\mathrm{CF}$ scoping above the negation is systematically blocked in the contexts discussed so far. The question that arises immediately is whether it is for semantic, pragmatic, or methodological reasons. It might be that the interpretation of (54) with the widest scope negation, as in (54-a), is easier to obtain than the interpretation of (54) with the widest scope existentially bound $\mathrm{CF}$, as in (54-b), and for that reason the language consultants gave the judgments along the interpretation of (54) given in (54-a). Definitely more semantic field research must be conducted which ideally would employ different methodologies, including experimental ones, in order to find out a source of the observed effect.

To sum up, in this section I argued that the proposed analysis of ko and kome as an existentially bound skolemized CF and a free skolemized CF, respectively, give proper results also in downward entailing contexts. It was important to show because downward entailing contexts were argued to be problematic for the analysis of indefinites as denoting CFs. In particular, Chierchia (2001) and Schwarz (2001, 2011) showed that a choice functional analysis of English indefinites predicts very weak truth-conditions and unattested readings in downward entailing contexts. It seems that $\mathrm{Ga}$ indefinites give rise precisely to these readings and therefore their analysis in terms of CFs can be sustained.

\section{Directions for Future Research}

In future research, the scopal properties of ko and kome with respect to other quantifiers and intensional predicates should be elicited. As for the scopal properties of ko and kome with respect to if-clauses, the relevant data are presented below: ${ }^{16}$

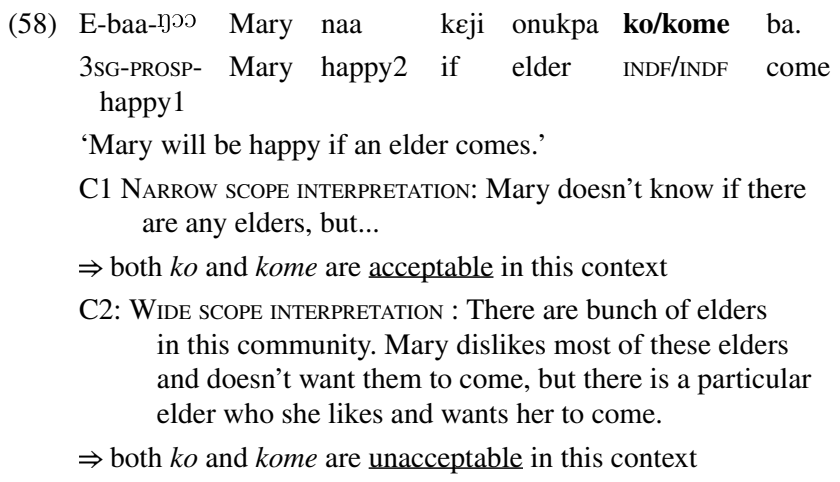

$\overline{16}$ The test is modeled following the examples in Matthewson (1999).
It turns out that both ko and kome can obtain a narrow scope interpretation with respect to if-clauses, as demonstrated by their acceptability in the context of (58-C1). However, they cannot obtain a wide scope interpretation with respect to if-clauses, as suggested by their unacceptability in the context of (58-C2). Nonetheless, since in order to account for the interaction of the semantics of indefinites with ifclauses, systematic field research on the semantics of conditionals needs to be conducted, it is left for future research.

Moreover, it should be examined empirically whether $k o$ and kome differ along some other dimensions than their scopal properties, especially that their distribution in some cases overlaps, as illustrated in Table 1. It should be verified whether they are semantically and pragmatically identical in these cases. In particular, it should be checked whether they give rise to existence, indifference or ignorance implications, identifiability or non-identifiability requirements, and epistemic specificity. ${ }^{17}$ The next step then would be to develop a unified analysis of indefinites in a cross-linguistic perspective.

\section{Summary}

In this paper, I provide empirical evidence that both existentially bound skolemized choice functions and free skolemized choice functions are attested in natural language. I particular, I analyzed the scopal properties of two indefinites in Ga: NP ko and NP kome. I propose that whereas ko denotes an existentially bound CF that takes a higher quantificational NP as its parameter (if available), kome denotes a free skolemized CF that always can take either the speaker or a higher quantificational NP as its parameter. Importantly, the data suggest that ko and kome, which obtain a choice-functional analysis, give rise to weak truth conditions and readings predicted by the choice functional analysis of indefinites but which are unattested in English. Thus the data from Ga shed new light on the semantics of indefinites and point to a variation in their analysis in a cross-linguistic perspective.

Open Access This article is distributed under the terms of the Creative Commons Attribution 4.0 International License (http:// creativecommons.org/licenses/by/4.0/), which permits unrestricted use, distribution, and reproduction in any medium, provided you give appropriate credit to the original author(s) and the source, provide a link to the Creative Commons license, and indicate if changes were made.

\footnotetext{
17 Thank you to the anonymous reviewer who asked about it.
} 


\section{References}

Barwise J, Cooper R (1981) Generalized quantifiers and natural language. Linguist Philos 4:159-219

Brasoveanu A, Farkas D (2011) How indefinites choose their scope. Linguist Philos 34:1-55

Chierchia G (2001) A puzzle about indefinites. In: Cecchetto C, Chierchia G, Guasti MT (eds) Semantic interfaces. CSLI, Stanford, pp 51-89

Farkas D (2002) Varieties of indefinites. Semant Linguist Theory 12:59-84

Fodor JD, Sag IA (1982) Referential and quantificational indefinites. Linguist Philos 5:355-398

Guerts B (2000) Indefinites and choice functions. Linguist Inq 4:731-738

Guerts B (2002) Specific indefinites, presupposition, and scope. In: Bäuerle R, Zimmermann TE (eds) Presuppositions and discourse. Elsevier, Oxford, pp 125-158

Heim I (1982) The semantics of definite and indefinite noun phrases. $\mathrm{PhD}$ Thesis, University of Massachusetts, Amherst

Heim I, Kratzer A (1998) Semantics in generative grammar. Blackwell, Oxford

Kamp H, Reyle U (1993) From discourse to logic. Kluwer, Dordrecht

Kratzer A (1998) Scope or pseudoscope? Are there wide-scope indefinites? In: Rothstein S (ed) Events and grammar. Kluwer Academic Publishers, Dordrecht
Kratzer A (2003) A note on choice functions in context. Ms. University of Massachusetts at Amherst

Matthewson L (2004) On the methodology of semantic fieldwork. Int J Am Linguist 70:369-415

Matthewson L (2001) Quantification and the nature of crosslinguistic variation. Nat Lang Semant 9:145-189

Matthewson L (1999) On the interpretation of wide-scope indefinites. Nat Lang Semant 7:79-134

Montague R (1973) The proper treatment of quantification in ordinary English. In: Hintikka J, Moravcsik J, Suppes P (eds) Approaches to natural language. Reidel, Dordrecht, pp 221-242

Reinhart T (1997) Quantifier scope: how labor is divided between QR and choice functions. Linguist Philos 20:335-397

Ross J (1967) Constraints on variables in syntax. PhD Thesis, Massachusetts Institute of Technology

Schwarz B (2001) Two kinds of long-distance indefinites. In: van Rooy R, Stokhof M (eds.) Proceedings of the 13th Amsterdam Colloquium. ICCL, Amsterdam, pp 192-197

Schwarz B (2011) Long distance indefinites and choice functions. Lang Linguist Compass 5(12):880-897

von Stechow A (2000) Some remarks on choice functions and LFmovement. In: von Heusinger K, Egli U (eds) Reference and anaphoric relations. Kluwer, Dordrecht, pp 193-228

Winter Y (1997) Choice functions and the scopal semantics of indefinites. Linguist Philos 20:399-467 